Eighteen months after the operation, the patient was without symptoms with a regimen of prednisone $25 \mathrm{mg} /$ day and a permanent immnunosuppressive therapy. Doppler echocardiography showed a well-functioning aortic prosthesis, no paraprosthetic leak, no false aneurysm, and a remaining thoracic aorta of normal caliber.

Discussion. Although the first aortic valve replacement in a patient with RP was reported in 1967, the ideal surgical procedure for such patients still remains to be determined. An extensive review of the literature reported by us in 1995 disclosed only 21 cases of aortic valve replacement, associated with mitral valve replacement in six and supracoronary graft replacement of the ascending aorta in three. ${ }^{1}$ All patients had aortic insufficiency related to aortic root enlargement $(77.7 \%)$ or exclusive valve involvement $(22.3 \%)$ or both mechanisms. All patients with aortic root involvement exhibited macroscopic or microscopic signs of aortitis. Six patients had an aneurysm of the ascending aorta within a mean 2.2-year postoperative delay. Three patients underwent reoperation for aortic prosthesis dehiscence with an operative mortality of $66.6 \%$; the three others died. In these patients, there is no doubt that corticosteroid therapy contributed to aortic tissue fragilization that resulted in suture leakage and prosthesis dehiscence. Also, two additional patients probably died of a ruptured ascending aorta within a 2-year postoperative delay (sudden death, no autopsy obtained). ${ }^{1}$ Consequently, we recommend a prophylactic Bentall-type operation in all patients with RP requiring aortic valve replacement. This procedure carries a minimal risk of morbidity/mortality and has proven to be safe and efficient in other diseases with aortic involvement, such as Marfan syndrome. ${ }^{2-5}$ Furthermore, we believe that the coronary button reimplantation technique associated with the exclusion technique for the aortic anastomoses is the most reliable method for prevention of bleeding and late false aneurysm formation at suture lines because all diseased aortic tissue is eliminated. 5 This option may prevent precoce or late anastomosis dehiscence and thus avoid further high-risk reoperations in fragile immunosuppressed patients.

\section{REFERENCES}

1. Lang-Lazdunski L, Hvass U, Paillole C, Pansard Y, Langlois J. Cardiac valve replacement in relapsing polychondritis. A review. J Heart Valve Dis 1995;4:227-35.

2. Gott VL, Pyeritz RE, Cameron DE, Greene PS, McKusik VA. Composite graft repair of Marfan aneurysym of the ascending aorta. Results in 100 patients. Ann Thorac Surg 1991;52:38-45.

3. Cohn L, Rizzo RJ, Adams DH, et al. Reduced mortality and morbidity for ascending aortic aneurysm resection regardless of cause. Ann Thorac Surg 1996;62:463-8.

4. Lewis CTP, Cooley DA, Murphy MC, Talledo O, Vega D. Surgical repair of aortic root aneurysms in 280 patients. Ann Thorac Surg 1992;53:38-46.

5. Kouchoukos NT, Wareing TH, Murphy SF, Perrillo JB. Sixteen-year experience with aortic root replacement. Results in 172 operations. Ann Surg 1991;214:308-20.

\title{
PERICARDIAL PATCH AUGMENTATION OF RESTRICTIVE INNOMINATE VEIN AND DIVISION OF LEFT SUPERIOR VENA CAVA IN UNROOFED CORONARY SINUS SYNDROME
}

\author{
Jacques A. M. van Son, MD, Volkmar Falk, MD, and Friedrich W. Mohr, MD, Leipzig, Germany
}

The unroofed coronary sinus syndrome is a spectrum of cardiac anomalies in which part or all of the common wall between the coronary sinus and the left atrium is absent; in most cases the anomaly is associated with a persistent left superior vena cava (SVC). ${ }^{1}$ In the absence of the coronary sinus, the left SVC connects with the left upper corner of the left atrium, between the opening of the left

From Herzzentrum, University of Leipzig, Leipzig, Germany.

Received for publication Oct. 21, 1996; accepted for publication Nov. 12, 1996.

Address for reprints: Jacques A. M. van Son, MD, Department of Cardiac Surgery, Herzzentrum Leipzig, Russenstrasse 19, Leipzig D-04289, Germany.

J Thorac Cardiovasc Surg 1997;114:132-4

Copyright (C) 1997 by Mosby-Year Book, Inc.

$0022-5223 / 97 \$ 5.00+0 \quad \mathbf{1 2 / 5 4 / 7 9 1 8 7}$ atrial appendage and the orifice of the left superior pulmonary vein. ${ }^{2}$ A coronary sinus atrial septal defect (ASD) is present in the posteroinferior region of the atrial septum, in the usual position of the coronary sinus orifice. The innominate vein is absent in $80 \%$ to $90 \%$ of patients with the unroofed coronary sinus syndrome and left SVC. ${ }^{3,4}$

The diagnosis of isolated unroofed coronary sinus syndrome with persistent left SVC usually is an indication for operation to avoid long-term arterial desaturation and its detrimental sequelae. In the absence of an innominate vein, the preferred repair consists of excision of the entire atrial septum except the anterior limbus, which is preserved as a protection for the atrioventricular node and bundle, ${ }^{5}$ followed by placement of a pericardial patch in such a fashion that all of the pulmonary veins drain under the patch to the mitral valve orifice. A second useful method of repair consists of rerouting the coronary sinus 


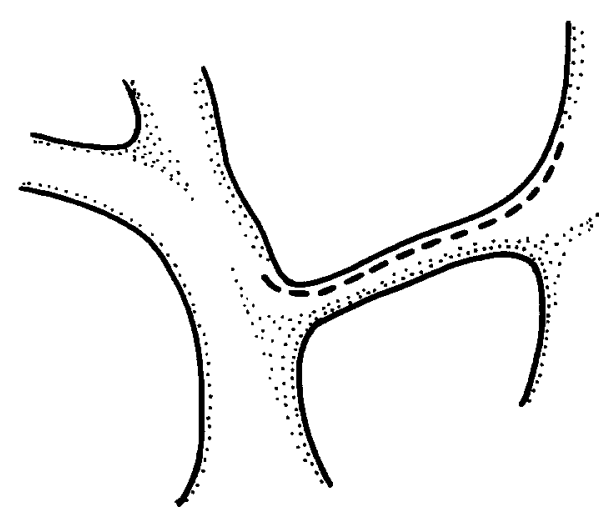

A

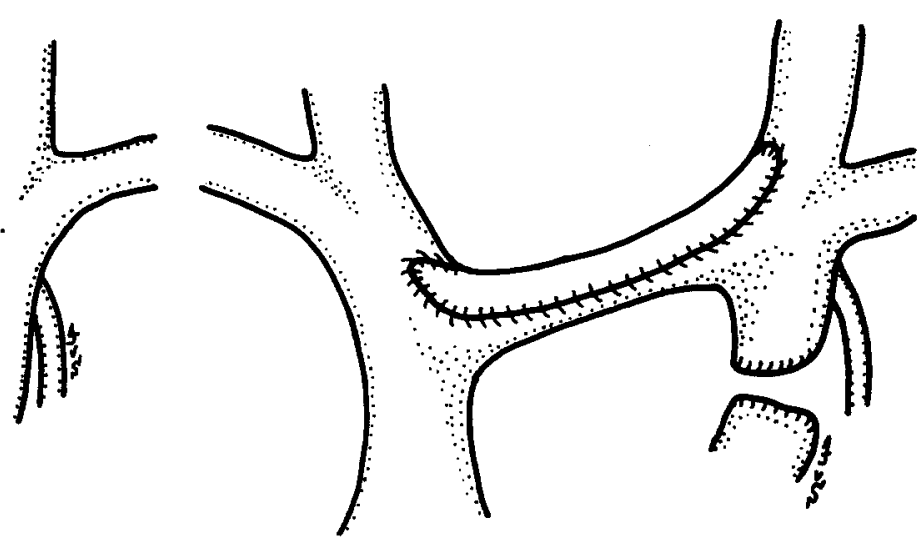

B

Fig. 1. Technique of repair of unroofed coronary sinus with persistent left SVC, coronary sinus ASD, and restrictive innominate vein. A, Dashed line indicates incision of superior aspect of innominate vein and proximal and medial aspects of the right brachiocephalic vein and the left internal jugular vein. B, Augmentation of innominate vein with untreated rectangular pericardial patch. The left SVC is divided and both ends are oversewn.

to the roof of the left atrium in addition to reconstruction of the atrial septum. ${ }^{6}$ In the presence of a physiologically unrestrictive or moderately restrictive innominate vein (defined as absence of a rise in pressure and a rise in pressure in the cranial left SVC to less than $20 \mathrm{~mm} \mathrm{Hg}$ resulting from temporary occlusion of the distal left SVC, respectively), the left SVC is simply divided and oversewn below the innominate vein and the coronary sinus ASD is closed with a patch. We report an alternative technique of repair of unroofed coronary sinus with left SVC that is applicable in the presence of a physiologically restrictive innominate vein.

A 9-week-old prematurely born female infant with a body weight of $3.1 \mathrm{~kg}$ was admitted for surgical correction of an echocardiographically diagnosed unroofed coronary sinus, left SVC, and coronary sinus ASD. The clinical picture was dominated by mild cyanosis (systemic arterial oxygen saturation of $94 \%$ ).

At operation through a median sternotomy, a left SVC was seen to enter the left superior portion of the left atrium; a small innominate vein (diameter $3 \mathrm{~mm}$ ) connected the two SVCs. Temporary occlusion of the left SVC close to its entrance into the left atrium increased the pressure in the cranial segment of the left SVC to $24 \mathrm{~mm} \mathrm{Hg}$. On the basis of this observation, ligation of the left SVC was deemed inappropriate. A large pericardial patch was harvested; the majority of the patch was stored in saline solution and the remainder in $0.6 \%$ glutaraldehyde solution. After aortic and single venous cannulation, the patient was rapidly cooled to a rectal temperature of $18^{\circ} \mathrm{C}$, circulatory arrest was established, and the venous and arterial cannulas were removed. An incision was made in the superior aspect of the innominate vein and the proximal $0.5 \mathrm{~cm}$ of the medial aspects of the right brachiocephalic vein and the left internal jugular vein, and a large rectangular untreated pericardial patch was sewn in place with 7-0 polypropylene suture (Prolene, Ethicon, Inc., Somerville, N.J.) in a continuous fashion (Fig. 1, $A$ and $B$ ). Subsequently, the left SVC was divided close to its entrance into the left atrium and both ends were oversewn with 6-0 Prolene suture. Finally, the coronary sinus ASD was closed with a glutaraldehyde-treated pericardial patch. After the infant was weaned from cardiopulmonary bypass, pressure measurements in the right brachiocephalic vein and the left internal jugular vein demonstrated absence of a pressure gradient between the two. The postoperative course was uncomplicated; notably, there was absence of facial edema, venous engorgement, or chylothorax. At 9-month follow-up, the infant is in excellent physical condition.

In unroofed coronary sinus with a persistent left SVC in the presence of a restrictive innominate vein, the technique of pericardial patch augmentation of the innominate vein, as reported here, may be a valuable alternative repair technique. The main advantage of this technique is avoidance of construction of a complex intraatrial baffle with its inherent potential complications related to the creation of a small and low-compliant left atrial compartment (with resultant impaired left ventricular filling) and pulmonary venous obstruction. Untreated pericardial patch is preferable to glutaraldehyde-treated pericardial patch for augmentation of the innominate vein, because the former is more mobile and pliable and therefore better adjusts to the low-pressure systemic venous system. We recommend anticoagulation treatment for an arbitrary period of 3 months to avoid thrombus formation in the patch-augmented innominate vein.

\section{REFERENCES}

1. Helseth HK, Peterson CR. Atrial septal defect with termination of left superior vena cava in the left atrium and absence of the coronary sinus: recognition and treatment. Ann Thorac Surg 1974;17:186-92.

2. Shumacker HB Jr, King H, Waldhausen JA. The persistent left superior vena cava: surgical implications, with special reference to caval drainage into the left atrium. Ann Surg 1967;165:797805 .

3. Sherafat M, Friedman S, Waldhausen JA. Persistent left 
superior vena cava draining into the left atrium with absent right superior vena cava. Ann Thorac Surg 1971;11:160-4.

4. Quaegebeur J, Kirklin JW, Pacifico AD, Bargeron LM Jr. Surgical experience with unroofed coronary sinus. Ann Thorac Surg 1979;27:418-25.

5. Chiu IS, Hegerty A, Anderson RH, de Leval M. The land- marks to the atrioventricular conduction system in hearts with absence or unroofing of the coronary sinus. J Thorac Cardiovasc Surg 1985;90:297-300.

6. Sand ME, McGrath LB, Pacifico AD, Mandke NV. Repair of left superior vena cava entering the left atrium. Ann Thorac Surg 1986;42:560-4.

\title{
REPAIR OF TRUNCUS ARTERIOSUS WITH INTACT VENTRICULAR SEPTUM (VAN PRAAGH TYPE B2) IN A NEONATE
}

\author{
Doff B. McElhinney, MS, ${ }^{\mathrm{a}}$ V. Mohan Reddy, MD, ${ }^{\mathrm{a}}$ Michael M. Brook, MD, ${ }^{\mathrm{b}}$ and Frank L. Hanley, MD, ${ }^{\mathrm{a}}$ \\ San Francisco, Calif.
}

Since Collett and Edwards ${ }^{1}$ and the Van Praaghs ${ }^{2}$ described their respective classifications of truncus arteriosus in 1949 and 1965, there has been extensive debate regarding the morphology and morphogenesis of lesions involving a common arterial trunk. ${ }^{3-5}$ Among the points of disagreement is the issue of whether truncus arteriosus can occur with an intact ventricular septum. Recently, we encountered a patient whose lesion was diagnosed before operation as truncus type A1/A2 but was found intraoperatively to have an intact ventricular septum and an abnormal truncal valve complex with separate orifices guarding the left and right ventricular outflow tracts.

Clinical summary. The patient was born after an uncomplicated term pregnancy and weighed 3145 grams at birth. Soon after birth, the patient began to have mild respiratory distress and received inpatient oxygen therapy for 3 days. A loud systolic murmur was detected at that time, and the patient underwent an initial cardiologic workup 6 days after birth. Echocardiography suggested a large single vessel arising from the heart, mainly committed to the right ventricle, a distorted single semilunar valve that was mildly stenotic and regurgitant, large pulmonary arteries arising from the trunk, and a secundum atrial septal defect. A diagnosis of truncus arteriosus type A1/A2 was made, and the patient was started on a regimen of digoxin and furosemide. The patient was referred to our institution for further evaluation and surgical treatment. At 28 days of age, an ascending aortogram was performed to better characterize the de-

From the Divisions of Cardiothoracic Surgery and Pediatric Cardiology, ${ }^{b}$ University of California, San Francisco, Calif.

Received for publication Nov. 27, 1996; accepted for publication Dec. 11, 1996.

Address for reprints: V. Mohan Reddy, MD, Division of Cardiothoracic Surgery, University of California, San Francisco, 505 Parnassus Ave., M593, San Francisco, CA 94143-0118.

J Thorac Cardiovasc Surg 1997;114:134-8

Copyright (C) 1997 by Mosby-Year Book, Inc.

0022-5223/97 $\$ 5.00+0 \quad \mathbf{1 2 / 5 4 / 7 9 7 8 2}$ gree of truncal insufficiency. Results were consistent with the typical angiographic appearance of truncus type A2 and confirmed mild regurgitation, apparently entirely into the right ventricle (Fig. 1). At 30 days of age, the patient underwent operation.

Externally, the lesion appeared to be a typical truncus type A2, with the two branch pulmonary arteries arising separately from the posterior aspect of the trunk approximately $5 \mathrm{~mm}$ above the sinotubular junction. After the initiation of bypass, aortic crossclamping, and the first dose of cardioplegia, the aorta was transected at the level of the pulmonary arteries, which were removed in continuity with the bridge of aortic tissue between them. The trunk at the level of transection was cylindric, with no aortopulmonary septal invagination. On looking down to inspect the valve, we observed that there was one valve anulus enclosing two orifices, with no ventricular septal defect. The left ventricular outflow tract appeared to have a gooseneck deformity but was intact. At the level of the semilunar valve, the left ventricular outflow tract was guarded by two fairly well-formed leaflets of the truncal valve, both of which originated from the lateral aspect of the anulus (opposite from the septal ridge). The right ventricular outflow tract was intact, but the truncal valve component guarding the orifice was dysmorphic, with essentially a large single leaflet attached laterally (away from the septal ridge). The valve tissue dividing the two orifices, which was directly resting on and fused to the ridge at the top of the conal septum, was rudimentary and extremely dysplastic on both sides; it exhibited almost no mobility. We considered this to represent an abnormal truncal valve (Fig. 2, A). A single coronary artery arose from the right-sided sinus above the left ventricular outflow tract.

A right atriotomy was performed and the atrial septal defect was closed to create a competent foramen ovale by tucking the septum primum under the limbus with a mattress suture. The ventricular septum was examined through the tricuspid valve, but no ventricular septal defect was identified. The right atriotomy was closed. We turned again to the two truncal valve orifices; the large 